\section{BMJ Paediatrics Open}

\title{
Early life antibiotics and childhood gastrointestinal disorders: a systematic review
}

\author{
Kim Kamphorst (D) , ${ }^{1,2}$ Emmy Van Daele (D) , ${ }^{3}$ Arine M Vlieger (D) ,2 \\ Joost G Daams (D) , ${ }^{4}$ Jan Knol (D) , ${ }^{3,5}$ Ruurd M van Elburg (i) ${ }^{1}$
}

To cite: Kamphorst $\mathrm{K}$, Van Daele E, Vlieger AM, et al. Early life antibiotics and childhood gastrointestinal disorders: a systematic review. BMJ Paediatrics Open 2021;5:e001028. doi:10.1136/ bmjpo-2021-001028

- Additional material is published online only. To view, please visit the journal online (http://dx.doi.org/10.1136/ bmjpo-2021-001028).

$\mathrm{KK}$ and EVD contributed equally.

KK and EVD are joint first authors.

Received 26 January 2021 Revised 8 February 2021 Accepted 10 February 2021

Check for updates

C Author(s) (or their employer(s)) 2021. Re-use permitted under CC BY-NC. No commercial re-use. See rights and permissions. Published by BMJ.

For numbered affiliations see end of article.

Correspondence to Dr Ruurd M van Elburg; rm. vanelburg@amsterdamumc.nl

\section{ABSTRACT}

Background In adults, there is increasing evidence for an association between antibiotic use and gastrointestinal (GI) disorders but in children, the evidence is scarce.

Objective Assess the association between exposure to antibiotics in the first 2 years of life in term born children and the presence of chronic Gl disorders later in childhood. Design For this systematic review the MEDLINE, Embase WHO trial register and Web of Science were systematically searched from inception to 8 June 2020. Title and abstract screening $(n=12219)$, full-text screening $(n=132)$ as well as the quality assessment with the Newcastle-Ottawa Scale were independently performed by two researchers. Main outcome measures The association between antibiotics and inflammatory bowel disease (IBD) $(n=6)$, eosinophilic oesophagitis $(E 0 E)(n=5)$, coeliac disease (CeD) $(n=6)$, infantile colics $(n=3)$, functional constipation $(n=2)$, recurrent abdominal pain, regurgitation, functional diarrhoea and infant dyschezia were examined.

Results Twenty-two studies were included, 11 cohort and 11 case-control studies. A best evidence synthesis showed strong evidence for an association between antibiotic exposure in the first 2 years of life and the presence of IBD, and CeD during childhood. Moderate evidence was found for an association with $\mathrm{E} 0 \mathrm{E}$ and no association with functional constipation in the first year of life. There was insufficient evidence for the other studied disorders.

Conclusions The use of antibiotics in early life may increase the risk of $\mathrm{Gl}$ disorders later in life. Further studies are necessary to unravel the underlying mechanisms and determine potential preventive measures. Meanwhile judicious use of antibiotics in early childhood is highly warranted.

PROSPERO registration number PROSPERO CRD42019132631.

\section{INTRODUCTION}

The incidence of paediatric gastrointestinal disorders (GI disorders), such as paediatric inflammatory bowel disease (IBD) and coeliac disease $(\mathrm{CeD})$, is rising. ${ }^{12}$ The increase in paediatric GI disorders is most likely related to environmental factors and recently the focus has been on the role of the intestinal microbiome. A microbiome that has been disturbed by factors like stress, dietary

\section{What is known about the subject?}

Evidence about the association between antibiotic use and gastrointestinal (Gl) disorders is increasing for adults, but in children the evidence remains scarce.

The incidence of $\mathrm{Gl}$ disorders in childhood is increasing.

\section{What this study adds?}

Antibiotics in early life may increase the risk of G disorders later in life especially inflammatory bowel disease and coeliac disease.

- Although functional Gl disorders are the most frequent in childhood, very few studies examined their association with antibiotics in early life.

change, environmental factors or drugs, can result in alterations in the immune system. ${ }^{3}$ Several studies have shown that a disturbed microbiome can be a cause or trigger of GI disorders, probably mediated by these immunological changes. ${ }^{4-7}$

One of the drugs with the most profound effect on the microbiome are antibiotics. ${ }^{8}$ The impact of antibiotics on the microbiome depends on various factors such as type of antibiotic, dosage and duration of exposure. Furthermore, age at exposure is probably also important. The gut of a newborn infant is almost sterile with a low diversity and matures according to several developmental stages with increasing diversity over time. ${ }^{9}$ The microbiome stabilises around the age of 2-3 years. ${ }^{9}$ Since this developing gut microbiota plays an important role in the training of both innate and adaptive immune system, it is likely that antibiotics will have their biggest impact when administered in the first 2 years of life.

For the association between antibiotic use and GI disorders, that has been shown in adults, ${ }^{10}$ there is only limited evidence in 


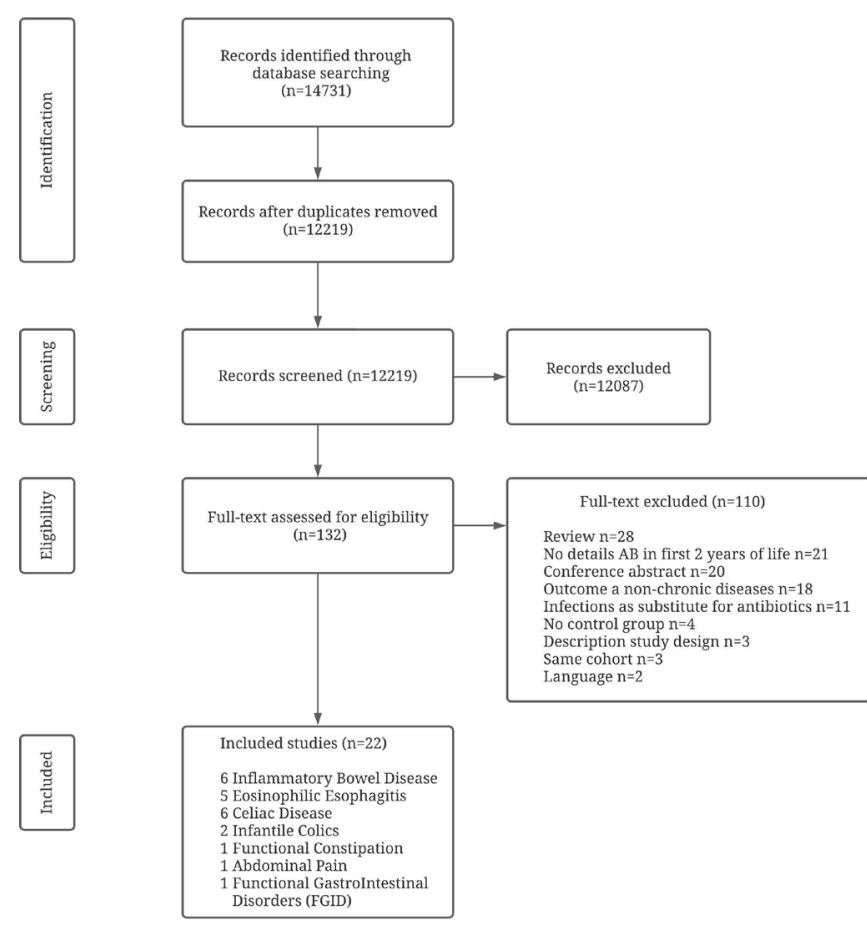

Figure 1 Preferred Reporting Items for Systematic Reviews and Meta-Analyses flow diagram of the study selection.

children. ${ }^{11}$ Therefore, the aim of this systematic review was to assess the association between exposure to antibiotics in the first 2 years of life and the presence of chronic GI disorders during childhood.

\section{METHOD}

\section{Study selection}

This systematic review was conducted according to the guidelines of the Preferred Reporting Items for Systematic Reviews and Meta-Analyses and registered in PROSPERO CRD42019132631. ${ }^{12}{ }^{13}$ MEDLINE, Embase, WHO trial register and Web of Science were systematically searched from inception to 8 June 2020 to identify all studies examining the association between antibiotic exposure in the first 2 years of life and the presence of common chronic (longer than 2 weeks, in order to exclude viral diarrhoea) GI disorders during the first 18 years of life. We searched for associations with IBD, eosinophilic oesophagitis (EoE), CeD, irritable bowel syndrome (IBS), (functional) abdominal pain (AP), constipation, dyspepsia, aerophagia, infantile colic, gastro-oesophageal reflux (GERD), regurgitation, dyschezia and chronic diarrhoea.

A multi stranded search approach comprised various concept combinations of children aged $0-4$ years, prognosis, GI disorders and antibiotics. In order to reduce recall noise and enhance search results precision we used VOS-viewer to identify terms for NOTing out irrelevant records from databases searched. ${ }^{14}{ }^{15}$ See online supplemental file 1 for the full search strategies.

\section{Patient and public involvement statement}

As this is a systematic review of the literature, there were no patients involved in the design of the research question nor the study itself. Furthermore, for the same reason no approval for the study was required from an ethical committee.

\section{In- and exclusion criteria}

Studies were included if: (1) antibiotics were administered between full-term birth and 2 years of age; (2) study outcome was diagnosis with a chronic GI disorder during the first 18 years of life; (3) antibiotic use was before the diagnosis of the GI disorder; (4) a control group was included; (5) in case multiple studies were found examining similar outcomes in one cohort, only the study with the largest cohort was included. No restrictions were placed on the time period of publication. Searches were limited to studies conducted in humans and excluded if the full text was not available in English, Dutch, German or French.

All records found in the search were exported into Rayyan after deduplication. ${ }^{16}$ Two researchers (KK and EVD) independently performed title and abstract screening as well as full-text screening. After consensus about the study selection, data were entered into a data extraction form, which included: author, year of publication, country, study design, cases, controls/cohort, population age, sample size exposed to antibiotics, age at exposure, details about classification by type of antibiotics, type of GI disorder, method of diagnosis, confounders for which corrected and the association between exposure and outcome.

\section{Methodological quality}

To assess the risk of bias, two researchers (KK and EVD) independently assessed the methodological quality. Discrepancies were resolved by discussion until consensus was reached. The Newcastle-Ottawa Scale (NOS) was used, which has been developed to assess the quality of observational studies. ${ }^{17}$ The NOS includes different instruments for assessing case-control and cohort studies. Both scales contain a maximum of nine points and assess studies in three core areas: (1) selection of study participants; (2) comparability of groups; (3) detection of exposure/outcome. One point for comparability of groups was given when the study controlled for the main important confounder and a second point if controlled for a second important confounder, see online supplemental file 2. Studies were rated high quality with a score of eight or higher, moderate quality with a score between five and seven and weak quality with a score of four or less. ${ }^{18}$

\section{Data analyses}

To synthesise the methodological quality of the studies, a commonly used best evidence synthesis was applied per disorder in which the methodological quality was considered according to the following definitions: (1) strong evidence, provided by generally consistent findings in 


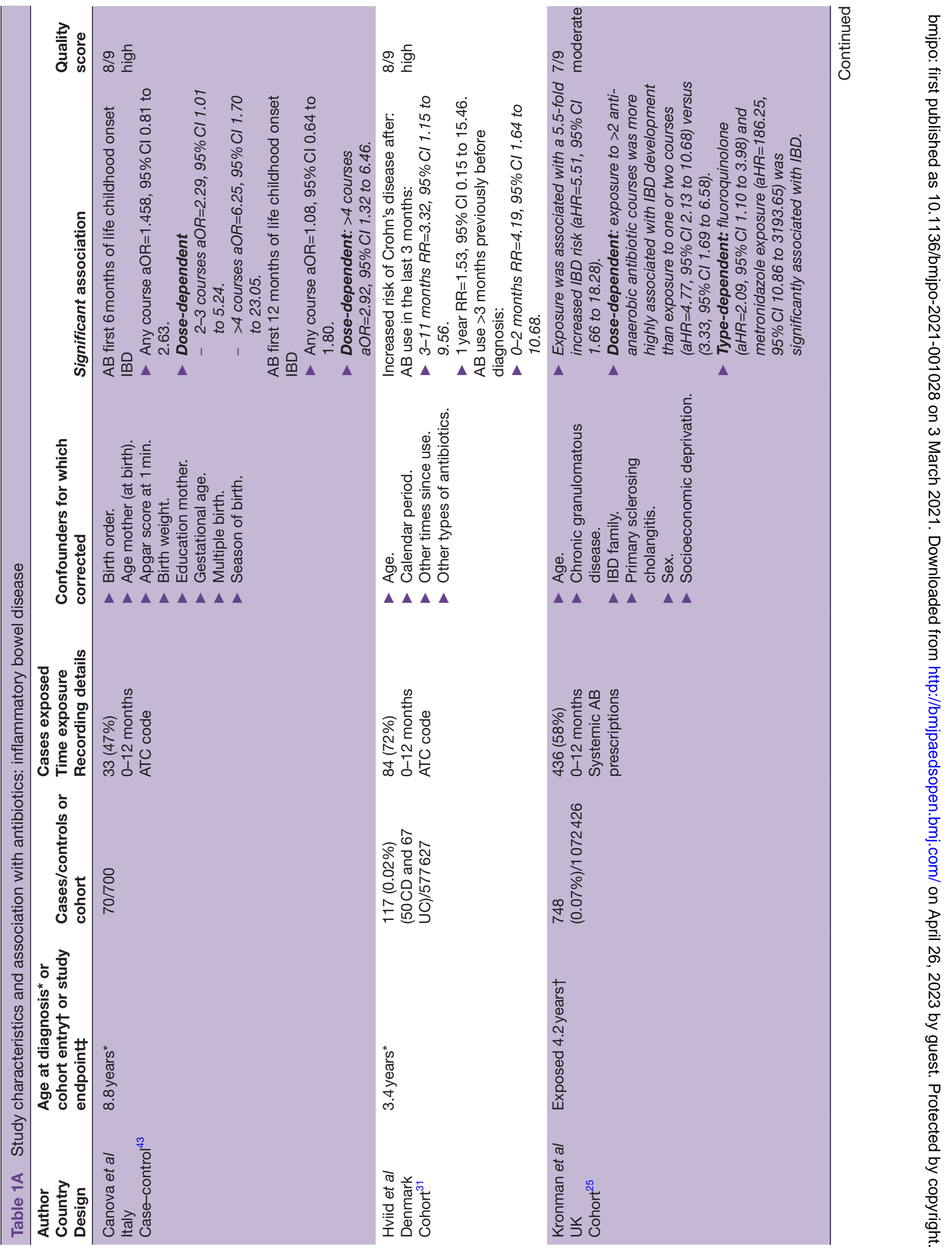




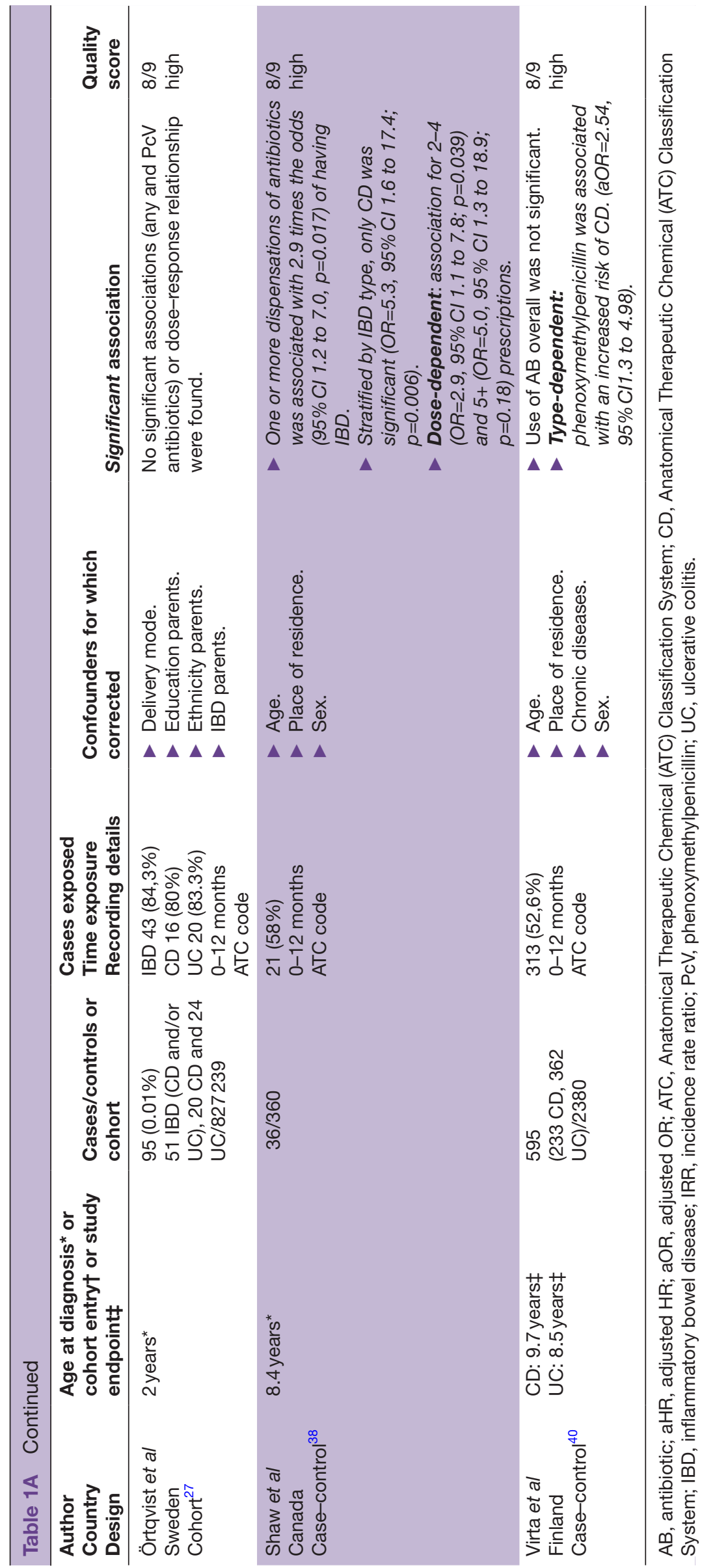


at least two high-quality studies; (2) moderate evidence, provided by generally consistent results in one highquality study and at least one moderate-quality or lowquality study, or generally consistent results in multiple moderate-quality or low-quality studies; (3) insufficient evidence, when less than two studies were available or inconsistent findings in multiple studies. ${ }^{19-21}$ Results were considered consistent when at least $75 \%$ of the studies showed results in the same direction.

\section{RESULTS}

\section{Search results}

Of the 14731 retrieved records, 12219 remained after removing duplicates. These records were screened; 132 were assessed as eligible and read in full-text of which 110 were excluded and 22 studies included in this review. Details of the selection procedure are shown in figure 1 .

\section{Study characteristics}

The included studies were published between 2010 and 2020 (tables 1A-D): 11 cohort studies ${ }^{22-32}$ and 11 case-control studies. ${ }^{33-43}$ The studies were performed in Sweden $(\mathrm{n}=4),{ }^{27} 303536$ the USA $(\mathrm{n}=5),{ }^{33} 34374142$ Italy $(\mathrm{n}=4),{ }^{22} 293243$ Denmark $(\mathrm{n}=2),{ }^{23} 31$ Canada $(\mathrm{n}=2)^{38} 39$ and one in the UK, ${ }^{25}$ the Netherlands ${ }^{26}$ and Finland. ${ }^{40}$ There were two international studies, one in Denmark and Norway, ${ }^{28}$ and another in Finland, Germany, Sweden and the USA. ${ }^{24}$

The associations between antibiotics and the following GI disorders were examined: IBD $(n=6), 252731384043$ EoE $(n=5),{ }^{33} 34373941 \mathrm{CeD}(\mathrm{n}=6),{ }^{22} 2428353642$ infantile colics $(n=3),{ }^{23} 2632$ functional constipation $(n=2),{ }^{29} 32$ recurrent AP $(\mathrm{n}=1) .{ }^{30}$ One study examined several functional GI disorders (FGIDs): infantile colics, functional constipation, functional diarrhoea, infant dyschezia and regurgitation. ${ }^{32}$

Exposure to antibiotics was studied in the first 2 years of life $(n=4),{ }^{24303542}$ the first 18 months of life $(n=1),{ }^{23}$ the first year of life $(n=13), 222527-2931333437-4043$ the first 6 months of life $(n=2)^{3641}$ and the first week of life $(\mathrm{n}=2)^{2632}$ (tables 1A-D). Since only a few studies provided details about type of antibiotics and/or number of antibiotic treatments in the first 2 years of life, the associations include mostly the overall antibiotic exposure.

\section{Quality assessment}

Ten studies were of high quality, 22 26-29 3135384043 ten studies moderate $23-2530323436374142$ and two weak ${ }^{33} 39$ (table 2). Frequently observed weaknesses were a high dropout rate in the cohort studies, assessment of antibiotic exposure through parental reports, and no correction for important confounders.

\section{Inflammatory bowel disease}

Exposure to early life antibiotics was associated with the development of IBD in five out of six studies 2531384043 (NOS=7,8,8,8,8), whereas no association was found in one study examining very early onset (VEO) IBD (before 6 years of age $)^{27}(\mathrm{NOS}=8)$. Three studies found a doseresponse relation ${ }^{253843}$ and an increased risk after fluoroquinolone,$^{25}$ metronidazole ${ }^{25}$ and phenoxymethylpenicillin ${ }^{40}$ exposure. In two studies IBD was stratified by type and only the OR for Crohn's disease, but not for ulcerative colitis, was significant. ${ }^{38}{ }^{40}$ Forest plots of the main results are shown in figure $2 \mathrm{~A}$.

\section{Eosinophilic oesophagitis}

In four of the five studies early life antibiotics was associated with $\mathrm{EoE}^{33} 343741$ (NOS=4,6,7,7), whereas in one study the rates of parental reported antibiotic use were similar for cases and controls ${ }^{39}$ (NOS=3) (figure 2B).

\section{Coeliac disease}

In four studies, of which three had a high quality, a significant association between early life antibiotics and the presence of $\mathrm{CeD}$ was found 22283542 (NOS=8,9,8,5), whereas in two moderate quality studies no association was found ${ }^{24}{ }^{36}$ (NOS=6,7) (figure 2C). Three studies showed a dose-response relationship between exposure to antibiotics and the risk of $\mathrm{CeD} .{ }^{22} 2842$ Furthermore, use of cephalosporin ${ }^{22}$ and multiple courses of macrolides ${ }^{24}$ showed a positive association with the development of CeD.

\section{Infantile colics}

Two studies found a significant association between early life antibiotics and infantile colics ${ }^{23}{ }^{26}$ (NOS=6,8), while one study found no association ${ }^{32}(\mathrm{NOS}=7)$ (figure 2D).

\section{Functional constipation}

In both studies, no association was found between early life antibiotic use and functional constipation in the first year of life ${ }^{29} 32$ (NOS=8,7).

\section{Recurrent AP}

The only study examining the association between antibiotic use in the first 2 years of life and the risk of recurrent $\mathrm{AP}$ at 12 years of age ${ }^{30}$ (NOS=5) found that only girls, but not boys, who received antibiotics in both the first and second year of life, had an increased risk of AP at 12 years.

\section{Regurgitation, dyschezia and functional diarrhoea}

In one study no association was found between antibiotics in the first week of life and regurgitation, dyschezia and functional diarrhoea ${ }^{32}$ (NOS=7).

\section{Syntheses of individual results}

Using the definitions for the best evidence synthesis, described in the method section, it can be concluded that there is strong evidence for an association of antibiotics in early life with IBD and CeD. There is moderate evidence for an association with $\mathrm{EoE}$ and no association with infantile constipation. The current evidence for an association between antibiotics in early life and the other studied GI disorders is considered insufficient. 


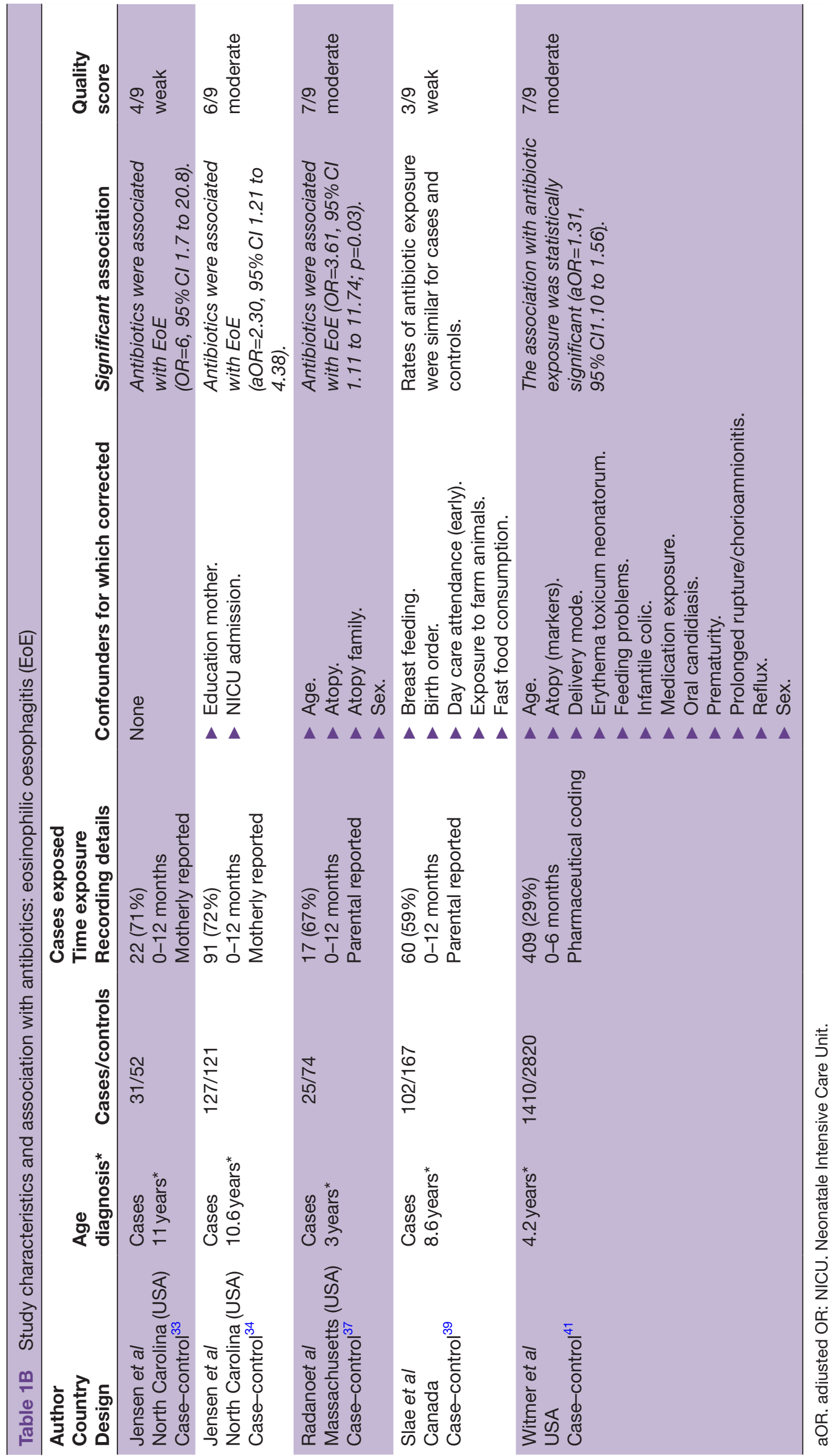




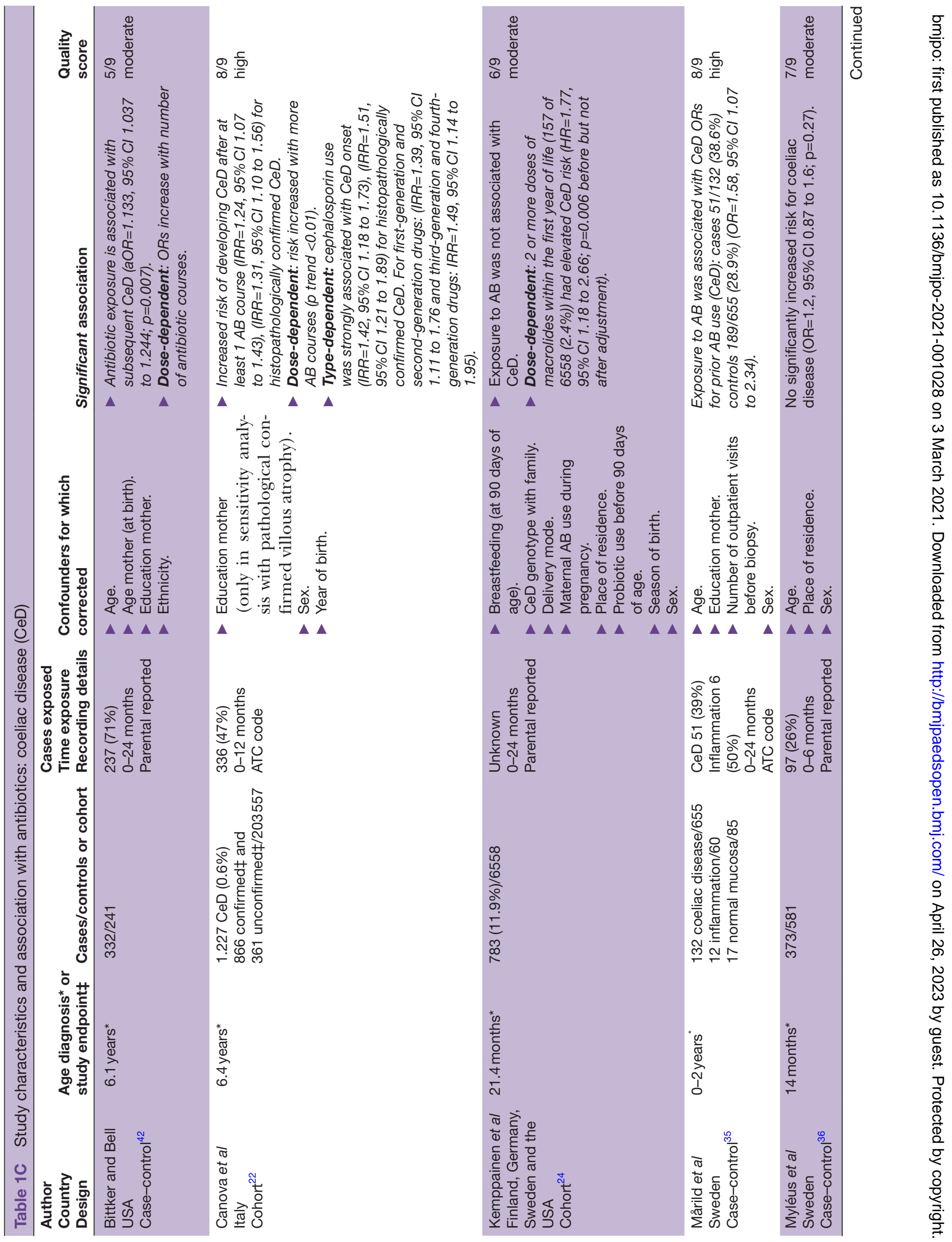




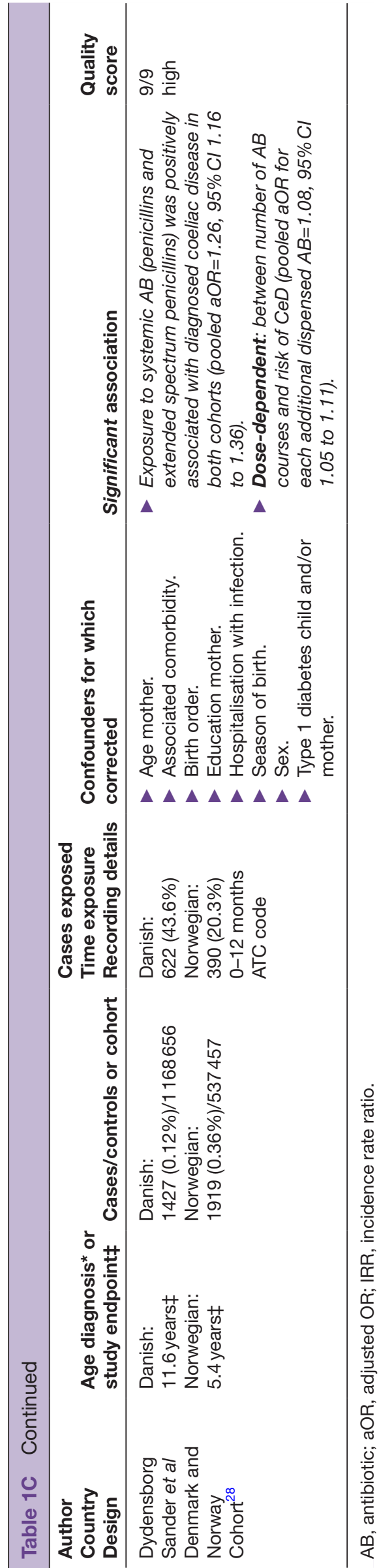

\section{DISCUSSION}

This systematic review with best evidence syntheses on the association between antibiotic exposure in the first 2 years of life and chronic GI disorders during childhood showed strong evidence for this association with IBD and $\mathrm{CeD}$, and moderate evidence for this association with EoE. For the other studied GI disorders, insufficient evidence was found.

The question remains to what extent the association with IBD, EoE and $\mathrm{CeD}$ can be attributed to antibiotic exposure itself or to other factors such as infections and parental health seeking behaviour. Infections in early life have been proposed to contribute to the development of chronic GI disorders ${ }^{44}$ and it is difficult to differentiate between the role of infections and antibiotics which are prescribed for (suspected) infections. Furthermore, several GI disorders like CeD can remain undiagnosed for a long time. Higher parental health seeking behaviour can both lead to higher use of antibiotics and a higher chance of diagnosing the chronic GI disorder. Therefore, it remains unknown whether antibiotics are the true causative agent in the observed associations or whether they are intermediates in different mechanistic pathways through microbiome perturbations or changes in immune development after (suspected) infections.

Most studies found a clear association between antibiotics in early life and IBD. The study that focused on VEO-IBD, found no association between antibiotics and VEO-IBD. VEO-IBD is considered a different entity from later-onset $\mathrm{IBD}^{44}{ }^{44}$ since genetics play a far more important aetiological role than microbial dysbiosis. ${ }^{45}$ This may explain the lack of an association with early life antibiotics.

The primary goal of antibiotic administration is to prevent detrimental effects of serious and sometimes even life-threatening infections. However, especially in early life, antibiotics are overused, since they are often prescribed for viral upper respiratory tract infections. ${ }^{46} 47$ Given its association with the occurrence of IBD, CeD and EoE, it is highly important to prevent antibiotic overuse by strict adherence to guidelines. If antibiotics are necessary, treatment would be adjusted to minimise dysbiosis. Another possible solution is to shorten the time of antibiotic administration. Oosterloo et al found more health issues in the first year of life after 7 days compared with 2 days of antibiotics in the first week of life. ${ }^{26}$ Furthermore, whenever possible, narrow-spectrum antibiotics rather than broad-spectrum should be used, because these specifically reduce the capacity of pathogens to cause disease while leaving commensals unharmed. ${ }^{48}$ If adjustment of antibiotic treatment is not possible, interventions that restore or prevent dysbiosis should be considered, such as administration of prebiotics or probiotics or faecal transplants. ${ }^{49-52}$

Some limitations of this review need to be considered. As no randomised controlled trials were available, only associations but not causality can be examined. Additionally, the studied results were not evaluated for their 


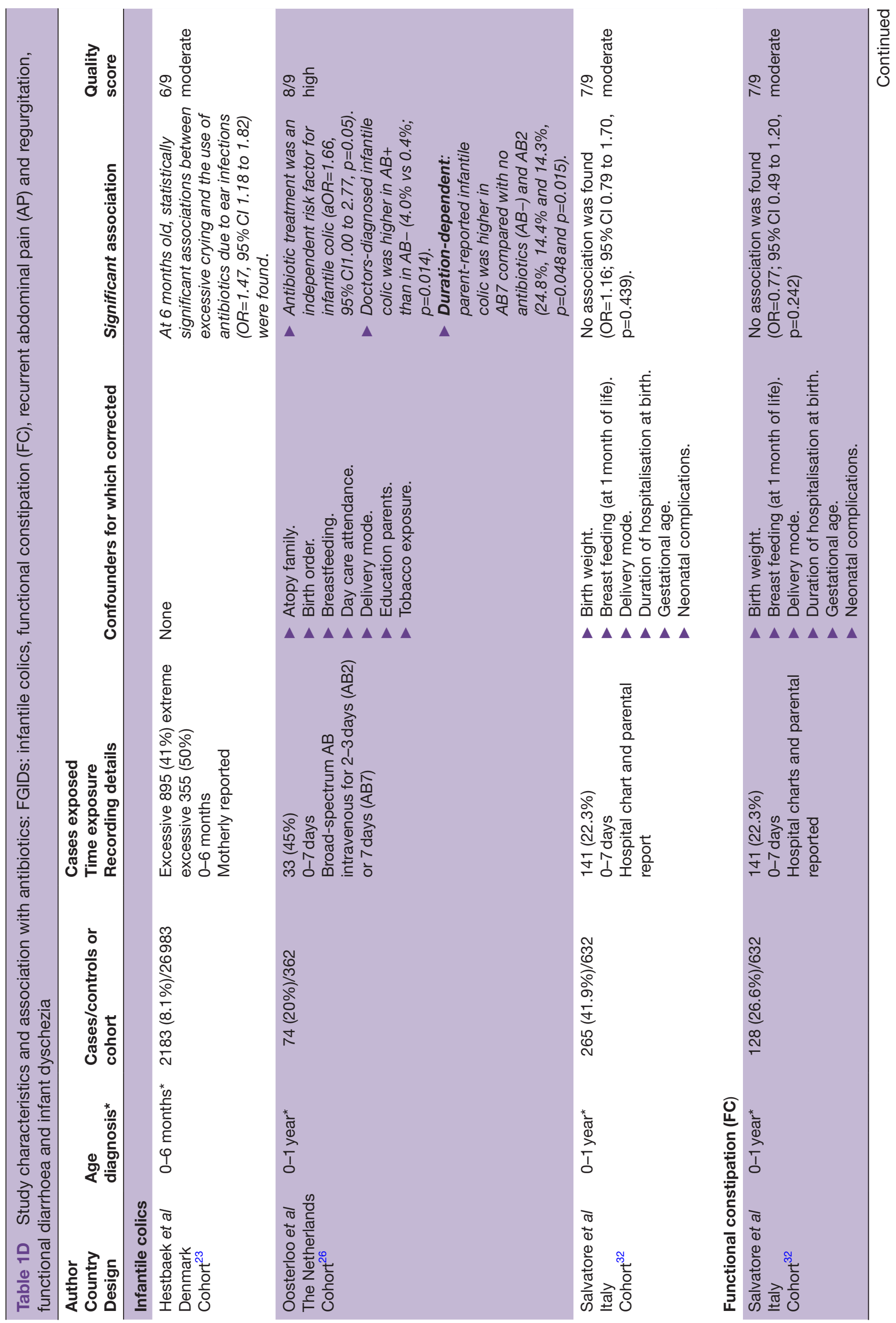




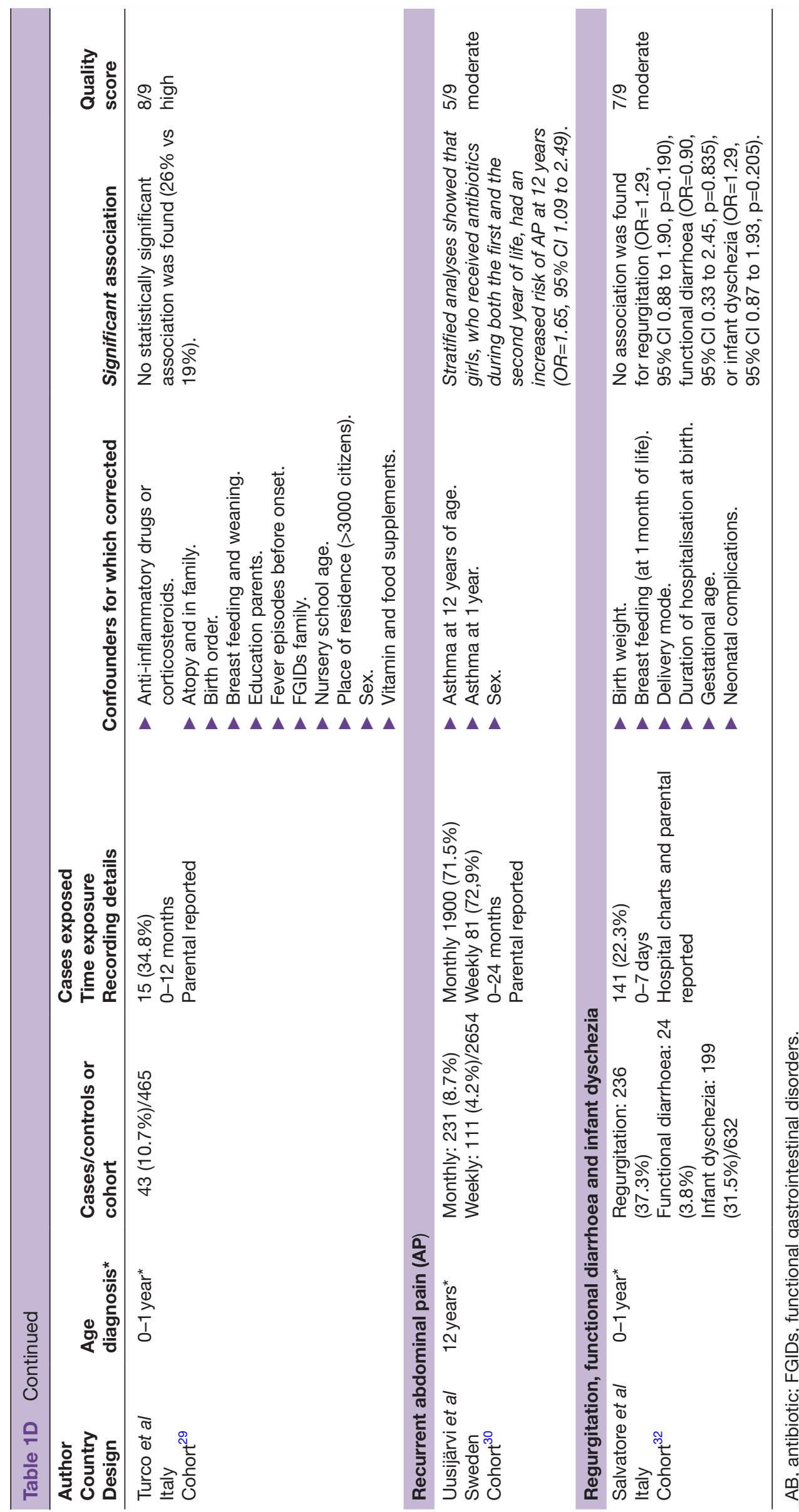



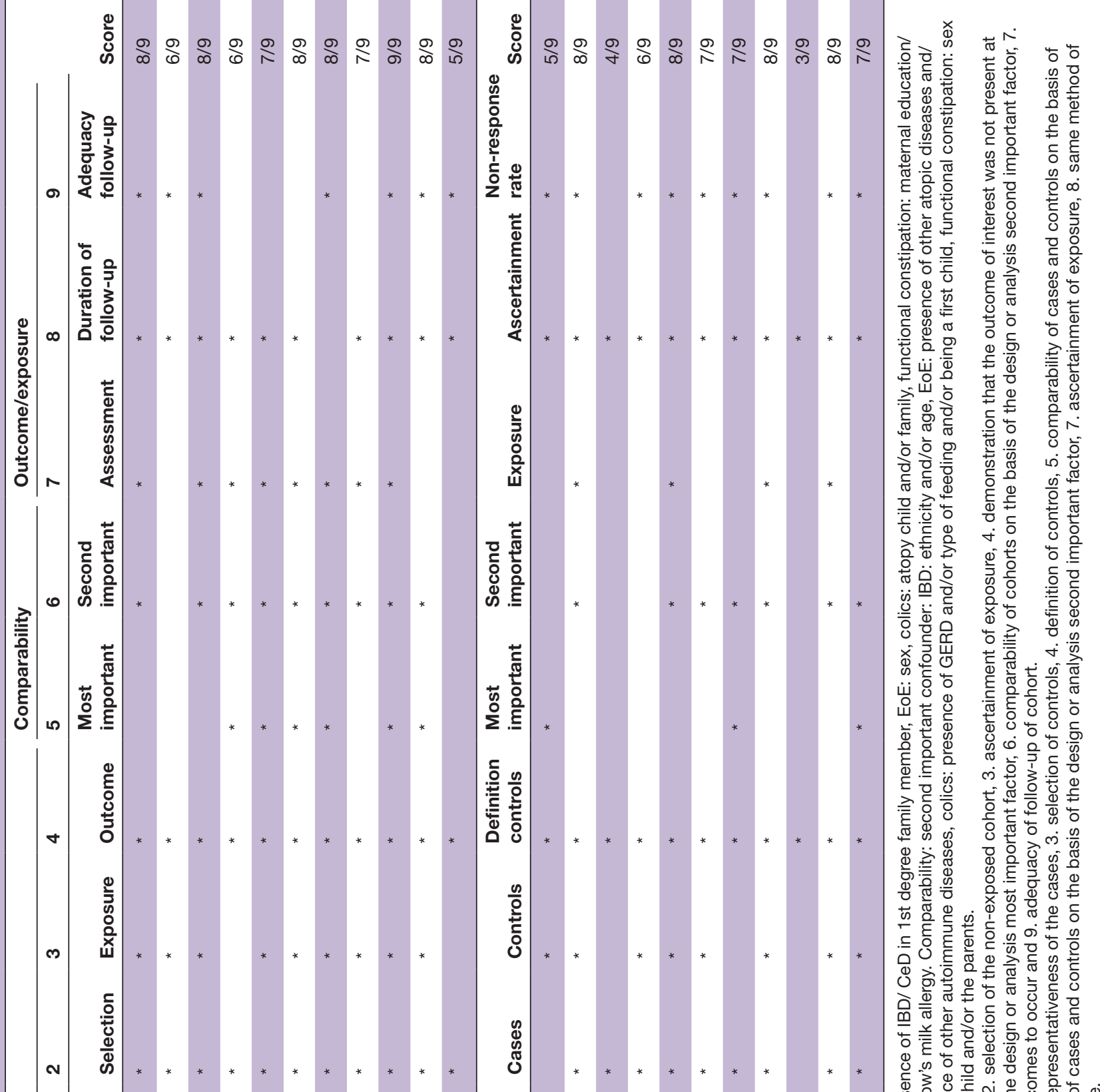

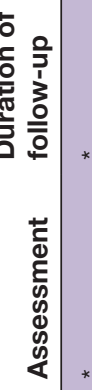

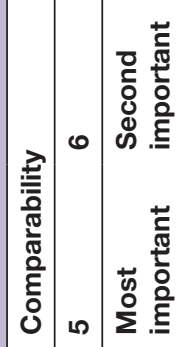

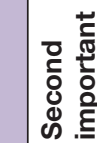

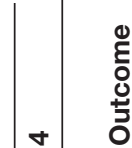

$₫$
$\vdots$
0
0
$\vdots$
0

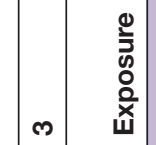

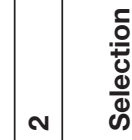

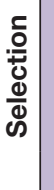
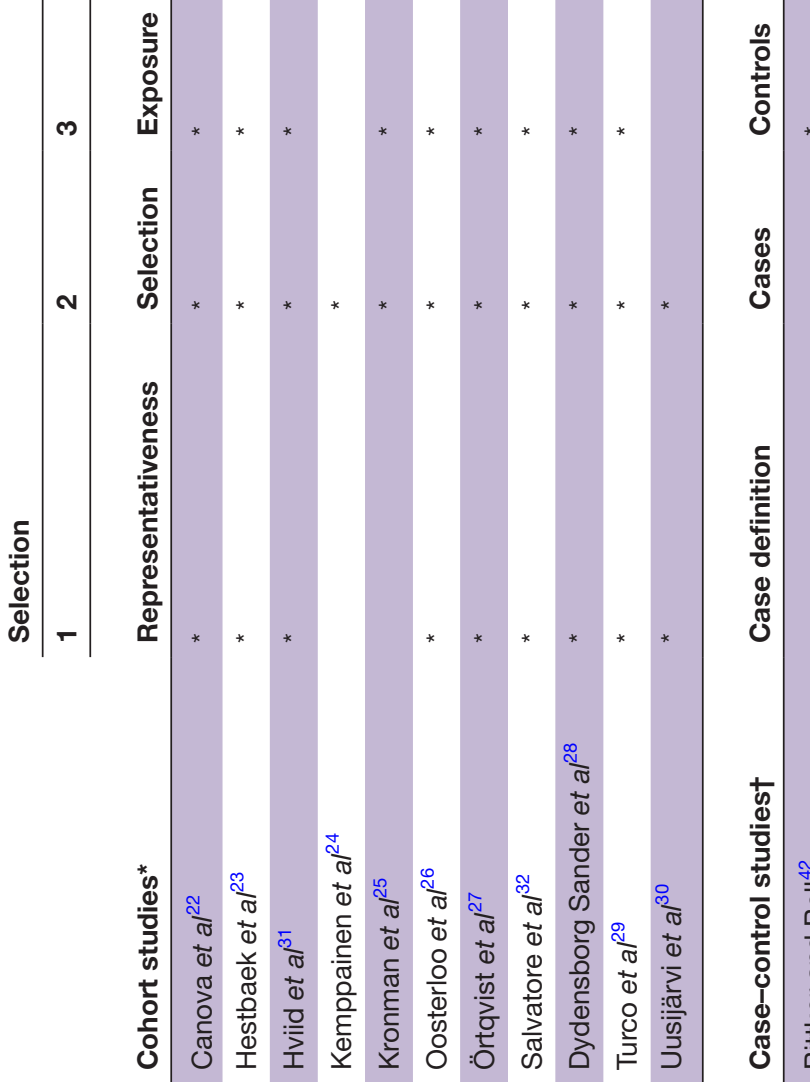

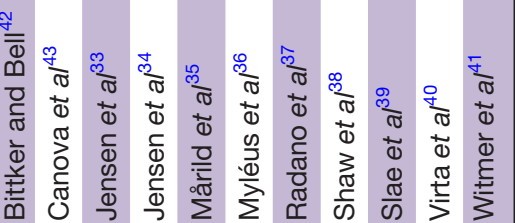

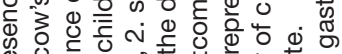

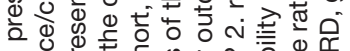
के

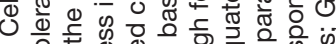

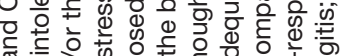

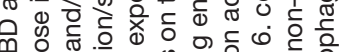
$\underline{0}$ 웅

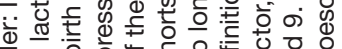

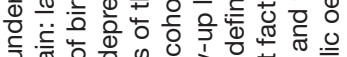

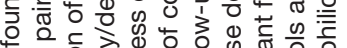

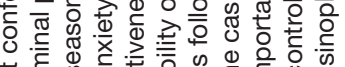

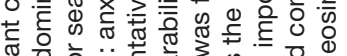

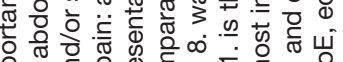
它 表 $\times$

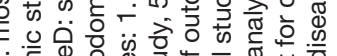

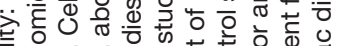

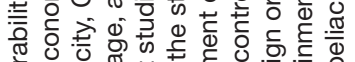

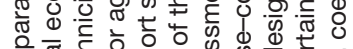

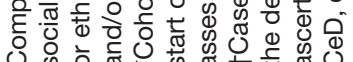




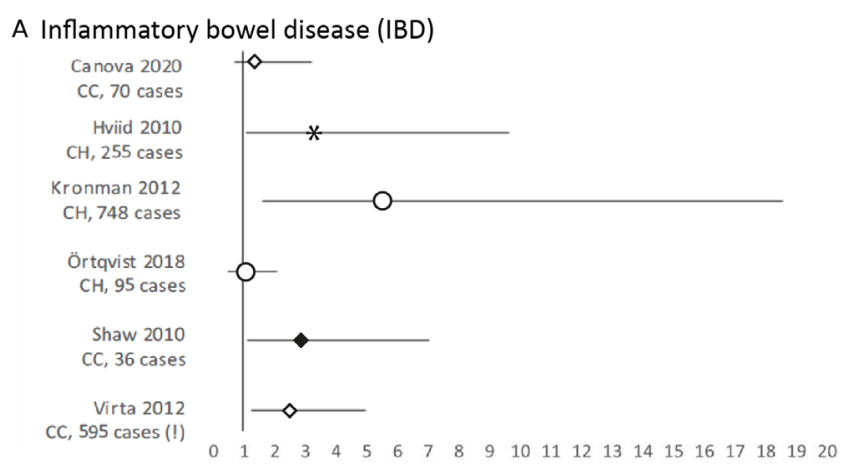

B Eosinophilic Esophagitis (EoE)

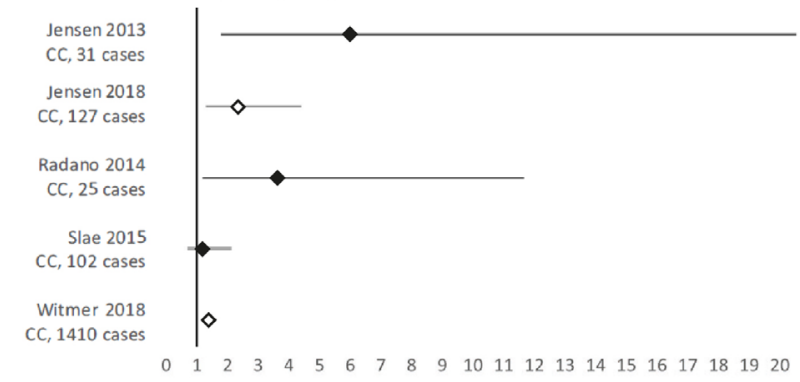

C Celiac disease (CeD)

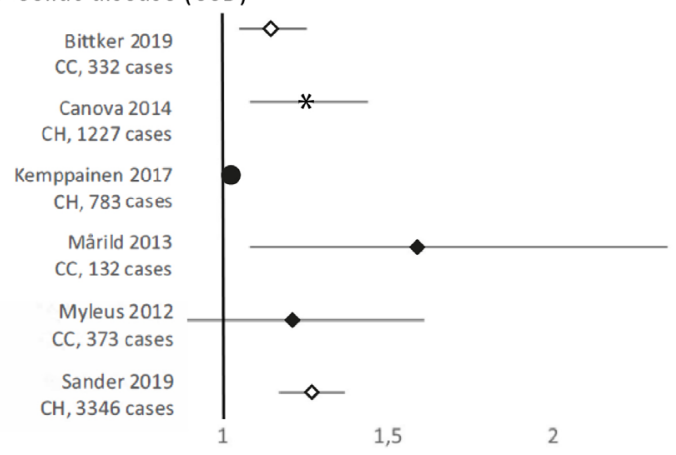

2,5

D Functional gastrointestinal disorders (FGIDs)

Infantile colics Hestbaek 2014 $\mathrm{CH}, 2183$ cases Oosterloo 2018 $\mathrm{CH}, 74$ cases

Salvatore 2019 $\mathrm{CH}, 255$ cases

Functional constipation

Salvatore 2019

$\mathrm{CH}, 128$ cases

Turco 2014 $\mathrm{CH}, 43$ cases 0,5

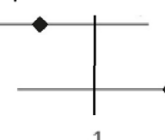

1 1,5 2,5 - confidence interval

OR/ $\diamond \mathrm{aOR} / *$ IRR/OHR/OaHR

Figure 2 Forest plots per gastrointestinal disorder. (A) IBD; (B) EoE; (C) CeD; (D) FGID (infantile colics and functional constipation). CC, case control study, $\mathrm{CH}$, cohort study, (!) Virta 2012 only shows the results of the phenoxymethylpenicillin analyses, overall use of antibiotics was not significant.

precision and associations with wide CIs can indicate uncertainty about the magnitude of the association. Hence, the results must be interpreted with caution. Furthermore, both age at exposure as well as age at diagnosis varied substantially between the studies. In addition, study outcomes were also very heterogeneous, excluding a meta-analysis. Therefore, a best evidence synthesis was applied, taking the quality of the studies into account. Furthermore, the recording of antibiotic exposure was in half of the studies parental reported, which may have led to recall bias. The antibiotics were mostly analysed as overall use, without distinguishing between types of antibiotics and therefore, it was not possible to determine associations between certain type of antibiotics and GI disorders. Finally, for several functional GI disorders, like IBS or GERD, only few or even no studies were found which prohibits any conclusions on these GI disorders.

One of the strengths of this review is that the search string was built and performed by an information scientist. Besides the published articles, also conference abstracts were checked for relevant studies. Furthermore, this review studies the association between antibiotics in early life and all chronic GI disorders in childhood, which provides insights in the available evidence but also shows the gap of knowledge for these associations.

For future research, it is recommended to study the association between early life antibiotics and the presence of those GI disorders that currently lack sufficient studies. Furthermore, it is necessary to gain insights in the specific effect of different types of antibiotics on the microbiome in order to optimise therapies that can prevent or counteract the detrimental effects of antibiotics in early life.

\section{CONCLUSION}

This systematic review shows strong evidence for an association between antibiotic exposure in the first 2 years of life and the presence of IBD and CeD later in childhood. For the other included GI disorders, only moderate or insufficient evidence was found. In order to decrease the incidence of IBD and CeD, antibiotic administration in early life should be critically considered. Moreover, interventions need to be developed to restore the microbiome after unavoidable antibiotic exposure in order to prevent detrimental health consequences later in life.

\section{Author affiliations}

${ }^{1}$ Pediatrics, Amsterdam Gastroenterology, Metabolism \& Nutrition, Amsterdam Reproduction \& Development Amsterdam, Amsterdam UMC Location AMC, Amsterdam, The Netherlands

${ }^{2}$ Paediatrics, Sint Antonius Ziekenhuis, Nieuwegein, The Netherlands

${ }^{3}$ Laboratory of Microbiology, Wageningen Universiteit en Research, Wageningen, The Netherlands

${ }^{4}$ Medical Library, Amsterdam UMC Location AMC, Amsterdam, The Netherlands

${ }^{5}$ Gut biology and microbiology, Danone Nutricia Research, Utrecht, The Netherlands

Contributors KK contributed to the design, the analyses and interpretation of the study, drafting of the initial manuscript, and reviewed and revised the manuscript. EVD contributed to the analysis and interpretation of the study and critically revised the manuscript. AMV and RMvE contributed to the conception of the study, interpretation of the data and critically revised the manuscript. JGD conceptualised and performed the systematic search and critically revised the manuscript. JK contributed to the conception and design of the study and critically revised the manuscript. All authors approved the final manuscript as submitted and agree to be accountable for all aspects of the work. 
Funding This study was funded by Nutricia Netherlands B.V. as part of a public private partnership and by the Christine Bader foundation (CBSIKZ).

Competing interests JK is a fulltime employee of Danone Nutricia Research (DNR), the PhD trajectory of EVD and KK are partly sponsored by DNR.

Patient consent for publication Not required.

Provenance and peer review Not commissioned; externally peer reviewed.

Data availability statement Data sharing not applicable as no datasets generated and/or analysed for this study. N/A.

Supplemental material This content has been supplied by the author(s). It has not been vetted by BMJ Publishing Group Limited (BMJ) and may not have been peer-reviewed. Any opinions or recommendations discussed are solely those of the author(s) and are not endorsed by BMJ. BMJ disclaims all liability and responsibility arising from any reliance placed on the content. Where the content includes any translated material, BMJ does not warrant the accuracy and reliability of the translations (including but not limited to local regulations, clinical guidelines, terminology, drug names and drug dosages), and is not responsible for any error and/or omissions arising from translation and adaptation or otherwise.

Open access This is an open access article distributed in accordance with the Creative Commons Attribution Non Commercial (CC BY-NC 4.0) license, which permits others to distribute, remix, adapt, build upon this work non-commercially, and license their derivative works on different terms, provided the original work is properly cited, appropriate credit is given, any changes made indicated, and the use is non-commercial. See: http://creativecommons.org/licenses/by-nc/4.0/.

\section{ORCID iDs}

Kim Kamphorst http://orcid.org/0000-0002-7081-9180

Emmy Van Daele http://orcid.org/0000-0003-0961-0481

Arine M Vlieger http://orcid.org/0000-0002-3869-2896

Joost G Daams http://orcid.org/0000-0002-8025-4961

Jan Knol http://orcid.org/0000-0002-2103-5961

Ruurd M van Elburg http://orcid.org/0000-0003-0310-6540

\section{REFERENCES}

1 Sýkora J, Pomahačová R, Kreslová M, et al. Current global trends in the incidence of pediatric-onset inflammatory bowel disease. World $J$ Gastroenterol 2018;24:2741-63.

2 King JA, Jeong J, Underwood FE, et al. Incidence of celiac disease is increasing over time: a systematic review and meta-analysis. Am J Gastroenterol 2020;115:507-25.

3 Levy M, Kolodziejczyk AA, Thaiss CA, et al. Dysbiosis and the immune system. Nat Rev Immunol 2017;17:219-32.

4 Bendtsen KM, Fisker L, Hansen AK, et al. The influence of the young microbiome on inflammatory diseases-Lessons from animal studies. Birth Defect Res C 2015;105:278-95.

5 Major G, Spiller R. Irritable bowel syndrome, inflammatory bowel disease and the microbiome. Curr Opin Endocrinol Diabetes Obes 2014;21:15-21.

6 Kennedy PJ, Cryan JF, Dinan TG, et al. Irritable bowel syndrome: a microbiome-gut-brain axis disorder? World J Gastroenterol 2014;20:14105.

7 Weber TK, Polanco I. Gastrointestinal microbiota and some children diseases: a review. Gastroenterol Res Pract 2012;2012:1-12.

8 laniro G, Tilg H, Gasbarrini A. Antibiotics as deep modulators of gut microbiota: between good and evil. Gut 2016;65:1906-15.

9 Bokulich NA, Chung J, Battaglia T, et al. Antibiotics, birth mode, and diet shape microbiome maturation during early life. Sci Transl Med 2016;8:343ra82.

10 Theochari NA, Stefanopoulos A, Mylonas KS, et al. Antibiotics exposure and risk of inflammatory bowel disease: a systematic review. Scand J Gastroenterol 2018;53:1-7.

11 Ungaro R, Bernstein CN, Gearry R, et al. Antibiotics associated with increased risk of new-onset Crohn's disease but not ulcerative colitis: a meta-analysis. Am J Gastroenterol 2014;109:1728-38.

12 Moher D, Liberati A, Tetzlaff J, et al. Preferred reporting items for systematic reviews and meta-analyses: the PRISMA statement. Int $J$ Surg 2010;8:336-41.

13 Page MJ, Shamseer L, Tricco AC. Registration of systematic reviews in Prospero: 30,000 records and counting. Syst Rev 2018;7:32.

14 Wilczynski NL, McKibbon KA, Haynes RB. Search filter precision can be improved by NOTing out irrelevant content. AMIA Annual Symposium Proceedings, American Medical Informatics Association, 2011:1506-13.
15 van Eck NJ, Waltman L. Software survey: VOSviewer, a computer program for bibliometric mapping. Scientometrics 2010;84:523-38

16 Ouzzani M, Hammady H, Fedorowicz Z, et al. Rayyan-a web and mobile APP for systematic reviews. Syst Rev 2016;5:210.

17 Wells GA SB, O'Connell D, Peterson J. The Newcastle-Ottawa scale (NOS) for assessing the quality of nonrandomised studies in metaanalyses. Ottawa Hospital Research Institute, 2019. http://www.ohri. $\mathrm{ca} /$ programs/clinical_epidemiology/oxford.asp

18 Wells G, Shea B, O'Connell D. Newcastle-Ottawa quality assessment form for cohort studies 2014:E17-18.

19 van Tulder M, Furlan A, Bombardier C, et al. Updated method guidelines for systematic reviews in the Cochrane collaboration back review group. Spine 2003;28:1290-9.

20 Veronese N, Solmi M, Luchini C, et al. Acetylcholinesterase inhibitors and memantine in bipolar disorder: a systematic review and best evidence synthesis of the efficacy and safety for multiple disease dimensions. J Affect Disord 2016;197:268-80.

21 Slavin RE. Best evidence synthesis: an intelligent alternative to meta-analysis. J Clin Epidemiol 1995;48:9-18.

22 Canova C, Zabeo V, Pitter G, et al. Association of maternal education, early infections, and antibiotic use with celiac disease: a population-based birth cohort study in northeastern Italy. Am J Epidemiol 2014;180:76-85.

23 Hestbaek L, Sannes MM, Lous J. Large cohort study finds a statistically significant association between excessive crying in early infancy and subsequent ear symptoms. Acta Paediatr 2014;103:e206-11.

24 Kemppainen KM, Vehik K, Lynch KF, et al. Association between early-life antibiotic use and the risk of islet or celiac disease autoimmunity. JAMA Pediatr 2017;171:1217-25.

25 Kronman MP, Zaoutis TE, Haynes K, et al. Antibiotic exposure and IBD development among children: a population-based cohort study. Pediatrics 2012;130:e794-803.

26 Oosterloo BC, van Elburg RM, Rutten NB, et al. Wheezing and infantile colic are associated with neonatal antibiotic treatment. Pediatr Allergy Immunol 2018;29:151-8.

27 Örtqvist AK, Lundholm C, Halfvarson J, et al. Fetal and early life antibiotics exposure and very early onset inflammatory bowel disease: a population-based study. Gut 2019;68:218-25.

28 Dydensborg Sander S, Nybo Andersen A-M, Murray JA, et al. Association between antibiotics in the first year of life and celiac disease. Gastroenterology 2019;156:2217-29.

29 Turco R, Miele E, Russo M, et al. Early-life factors associated with pediatric functional constipation. J Pediatr Gastroenterol Nutr 2014;58:307-12.

30 Uusijärvi A, Bergström A, Simrén M, et al. Use of antibiotics in infancy and childhood and risk of recurrent abdominal pain--a Swedish birth cohort study. Neurogastroenterol Motil 2014;26:841-50.

31 Hviid A, Svanström H, Frisch M. Antibiotic use and inflammatory bowel diseases in childhood. Gut 2011;60:49-54.

32 Salvatore S, Baldassarre ME, Di Mauro A, et al. Neonatal antibiotics and prematurity are associated with an increased risk of functional gastrointestinal disorders in the first year of life. $J$ Pediatr 2019;212:44-51.

33 Jensen ET, Kappelman MD, Kim HP, et al. Early life exposures as risk factors for pediatric eosinophilic esophagitis. J Pediatr Gastroenterol Nutr 2013;57:67-71.

34 Jensen ET, Kuhl JT, Martin LJ, et al. Prenatal, intrapartum, and postnatal factors are associated with pediatric eosinophilic esophagitis. J Allergy Clin Immunol 2018:141:214-22.

35 Mårild $\mathrm{K}, \mathrm{Ye} \mathrm{W}$, Lebwohl $\mathrm{B}$, et al. Antibiotic exposure and the development of coeliac disease: a nationwide case-control study. BMC Gastroenterol 2013;13:109.

36 Myléus A, Hernell O, Gothefors L, et al. Early infections are associated with increased risk for celiac disease: an incident casereferent study. BMC Pediatr 2012;12:194.

37 Radano MC, Yuan Q, Katz A, et al. Cesarean section and antibiotic use found to be associated with eosinophilic esophagitis. J Allergy Clin Immunol Pract 2014;2:475-7.

38 Shaw SY, Blanchard JF, Bernstein CN. Association between the use of antibiotics in the first year of life and pediatric inflammatory bowel disease. Am J Gastroenterol 2010;105:2687-92.

39 Slae M, Persad R, Leung AJ-T, et al. Role of environmental factors in the development of pediatric eosinophilic esophagitis. Dig Dis Sci 2015;60:3364-72.

40 Virta L, Auvinen A, Helenius $\mathrm{H}$, et al. Association of repeated exposure to antibiotics with the development of pediatric Crohn's disease--a nationwide, register-based finnish case-control study. Am J Epidemiol 2012:175:775-84. 
41 Witmer CP, Susi A, Min SB, et al. Early infant risk factors for pediatric eosinophilic esophagitis. J Pediatr Gastroenterol Nutr 2018;67:610-5.

42 Bittker SS, Bell KR. Potential risk factors for celiac disease in childhood: a case-control epidemiological survey]]\&gt. Clin Exp Gastroenterol 2019;12:303-19.

43 Canova C, Ludvigsson JF, Di Domenicantonio R, et al. Perinatal and antibiotic exposures and the risk of developing childhood-onset inflammatory bowel disease: a nested case-control study based on a population-based birth cohort. Int J Environ Res Public Health 2020;17:2409.

44 Bernstein CN, Burchill C, Targownik LE, et al. Events within the first year of life, but not the neonatal period, affect risk for later development of inflammatory bowel diseases. Gastroenterology 2019;156:2190-7.

45 Jiang $\mathrm{H}-\mathrm{Y}$, Zhang $\mathrm{X}$, Zhou Y-Y, Hy J, Yy Z, et al. Infection, antibiotic exposure, and risk of celiac disease: a systematic review and metaanalysis. J Gastroenterol Hepatol 2020;35:557-66.
46 van Houten CB, Naaktgeboren C, Buiteman BJM, et al. Antibiotic overuse in children with respiratory syncytial virus lower respiratory tract infection. Pediatr Infect Dis J 2018;37:1077-81.

47 Arnolda G, Hibbert P, Ting HP, et al. Assessing the appropriateness of paediatric antibiotic overuse in Australian children: a populationbased sample survey. BMC Pediatr 2020;20:1-8.

48 Melander RJ, Zurawski DV, Melander C. Narrow-spectrum antibacterial agents. Medchemcomm 2018;9:12-21.

49 McFarland LV. Use of probiotics to correct dysbiosis of normal microbiota following disease or disruptive events: a systematic review. BMJ Open 2014;4:e005047.

50 Kumar R, Sood U, Gupta V, et al. Recent advancements in the development of modern probiotics for restoring human gut microbiome dysbiosis. Indian J Microbiol 2020;60:1-14.

51 Chua MC, Ben-Amor K, Lay C, et al. Effect of synbiotic on the gut microbiota of cesarean delivered infants: a randomized, doubleblind, multicenter study. J Pediatr Gastroenterol Nutr 2017;65:102-6.

52 Langdon A, Crook N, Dantas G. The effects of antibiotics on the microbiome throughout development and alternative approaches for therapeutic modulation. Genome Med 2016;8:39. 